\title{
Effects of whole body vibration on biogenic amines in
} rat brain

\author{
M ARIIZUMI AND A OKADA
}

From the Department of Public Health, School of Medicine, Kanazawa University, Kanazawa 920, Japan

ABSTRACT The effects of whole body vibration on the concentrations of noradrenaline (NA), dopamine (DA), and serotonin (5-HT) in the whole brain and brain regions of rats were investigated. Compared with control rats, vibration with $20 \mathrm{~Hz}$ frequency decreased the brain concentration of NA only when the acceleration (intensity) was increased to $5.0 \mathrm{G}(\mathrm{p}<0.05$ ). The concentration of DA in the whole brain was not affected by acceleration. When acceleration was kept at a constant $0.4 \mathrm{G}$ level and rats were exposed for the same 240 minute period to 5,20 , or $30 \mathrm{~Hz}$ vibration, neither NA nor DA concentrations changed in the whole brain. Regional changes in the concentration of biogenic amines in the brain of rats exposed to vibration of $20 \mathrm{~Hz}$ and $5.0 \mathrm{G}$ showed few significant differences. Thus NA significantly decreased only in the hypothalamus $(\mathrm{p}<0.01)$, although in the hippocampus the decrease was nearly significant $(\mathrm{p}<$ $0 \cdot 10)$. The concentration of 5-HT significantly increased in the hypothalamus and cerebellum $(p<0.05)$. DA tended to increase in the cortex and decrease in the striatum $(p<0 \cdot 10)$. These experiments seem to indicate that NA in the whole brain and especially in the hypothalamus is a better indicator of vibration exposure than 5-HT, and that NA is affected by the intensity but not by the frequency of vibration. NA and 5-HT in the hypothalamus change in the opposite direction. DA concentrations in the brain are basically unaffected by vibration.

Vibrations received by some sensory organs, such as the pacinician corpuscles, travel through the spinal cord to reach the hypothalamus and the cerebral cortex where the information is recognised. The responses of the central nervous system to whole body vibration have not been clarified. Therefore it was thought that the investigation of the changes in the concentration of biogenic amines in the brain would be an important step in the study of the biochemical effects of vibration on the central nervous system. The study was also intended to obtain information on regional differences in vibration induced changes in the concentration of the following amines, noradrenaline (NA), dopamine (DA), and serotonin (5-HT).

\section{Materials and methods}

Male Wistar rats, weighing 200-250 g (average $242 \mathrm{~g}$ ) were used in the study. The rats were divided into 10 groups each of four rats. Four groups were used to test different frequencies and four to test

Received 10 January 1983

Accepted 2 April 1984 different accelerations; the other two groups were used to study regional changes. During the preexperimental period all the rats were in light from $8 \mathrm{am}$ to $8 \mathrm{pm}$ and in darkness for the remaining time; the room temperature was fixed at $23 \pm 2^{\circ} \mathrm{C}$, and food and water were provided freely.

The apparatus for vibration exposure consisted of an electromagnetic shaker (EMIC 513-A) coupled to an amplifier (Tachikawa TA-100), function oscillator (NF-Model E-1011), and a vibration meter (EMIC 505-D). The animals were subjected to vertical sinusoidal whole body vibrations for 240 minutes. Throughout the experiments both exposed and control animals were individually kept in the prone position in wire mesh cages that were tightly fixed on the vibrating plate. Before the experiment began the rats were kept in the same wire mesh cages for four hours a day for one week - that is, for the time of the vibration exposure to adapt them to the experimental conditions.

Accelerations were $0.4 \mathrm{G}, 2.0 \mathrm{G}$, or $5.0 \mathrm{G}$ under a constant vibration frequency of $20 \mathrm{~Hz}$; frequencies were $5.0 \mathrm{~Hz}, 20 \mathrm{~Hz}$, or $30 \mathrm{~Hz}$ under a constant acceleration of $0.4 \mathrm{G}$. In the regional brain studies an acceleration of $5.0 \mathrm{G}$ and a vibration frequency 
of $20 \mathrm{~Hz}$ were used for 240 minutes. All the exposures were carried out between 9 am and $1 \mathrm{pm}$. Rats placed near the electromagnetic shaker and therefore exposed to noise without vibration were used as controls. The rats were decapitated immediately after the exposure and the brain was quickly removed from the cranium, placed on an ice plate, and washed with physiological saline solution. Blood was blotted from the brain which was weighed and kept in a deep freezer $\left(-80^{\circ} \mathrm{C}\right)$ until the amine assays were performed. For regional studies the brain was divided into the following regions on the ice plate: cerebellum, meddulla oblongata, hypothalamus, striatum, midbrain, cortex, and hippocampus according to the method described by Glowinski and Iversen. ${ }^{1}$ Each region was weighed and kept in a deep freezer until assayed.

The levels of NA, DA, and 5-HT were determined after homogenisation in $0.4 \mathrm{~N}$ perchloric acid. The three amines were eluated on an Ambelite CG-50 column and the levels of NA and DA in the eluate were fluorometrically determined by the trihydroxyindole method and dihydroxyindole method respectively as described by Karasawa et al. ${ }^{2}$ The level of 5-HT was determined by the fluorometric method of Bogdanski et al. ${ }^{3}$

A Teflon homogeniser (OMEGA electric type SM-3, Takashima Co) was used for brain homogenisation, and a fluorospectrophotometer (Farrand MK-1) was used for the fluorometric assay of amines.

The data were subjected to statistical analysis using Student's $t$ test. Significant values of $p<0.05$ and $p<0.01$ were regarded as significant; a $p$ value $<0 \cdot 10$ was considered as suggestively significant.

\section{Results}

\section{ACCELERATION AND BRAIN NA AND DA}

\section{CONTENTS}

Figure 1 shows the responses of NA and DA in the whole brain to increasing acceleration under a constant frequency of $20 \mathrm{~Hz}$. The NA content in the $5.0 \mathrm{G}$ exposure group was significantly $(p<0.05)$ decreased (by $57 \%$ ) compared with that of the control group. Moreover there was a significant difference $(p<0.01)$ between the mean values in the group exposed to $0.4 \mathrm{G}$ and the group exposed to $5.0 \mathrm{G}$. There were no remarkable differences in the concentrations of DA in the whole brain.

FREQUENCY AND BRAIN NA AND DA CONTENTS Figure 2 shows the responses of NA and DA in the whole brain to increasing frequency at constant acceleration $(0.4 \mathrm{G})$. There were no differences in either NA or DA concentrations.

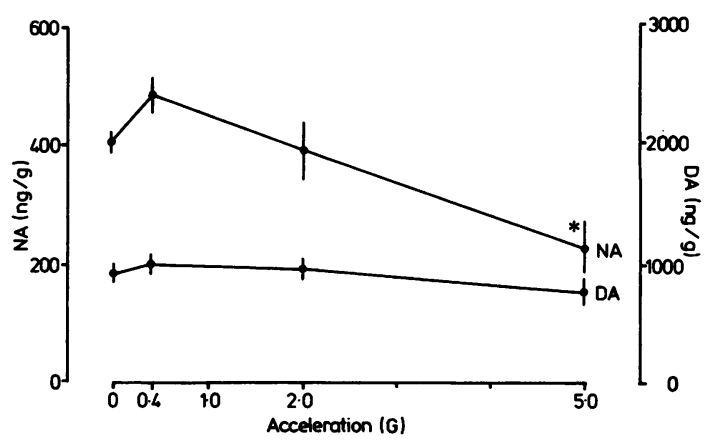

Fig 1 Effects of 240 minute vibration of different intensity (acceleration) at constant frequency of $20 \mathrm{~Hz}$ on brain NA and DA concentrations. Each point represents mean \pm $S E M$ of four rats. ${ }^{*} p<0.05$ ( $t$ test).

\section{NA, DA, AND 5-HT CONCENTRATIONS IN BRAIN REGIONS}

Figure 3 shows NA concentrations in each of the seven regions in control rats and rats exposed for 240 minutes to vibration of $20 \mathrm{~Hz}$ and $5.0 \mathrm{G}$. Of the seven regions, NA concentration was significantly decreased only in the hypothalamus $(p<0.01)$ and suggestively in the hippocampus $(p<0 \cdot 10)$. Figure 3 also shows significant $(p<0.05)$ increases in the 5-HT contents of the cerebellum and hypothalamus.

Regional distribution of DA showed a nonsignificant increase $(p<0.10)$ in the cortex and a decrease $(p<0 \cdot 10)$ in the striatum (fig 4$)$.

\section{Discussion}

Some authors have shown changes in the concentration of NA, 5-HT, and DA in the whole brain or

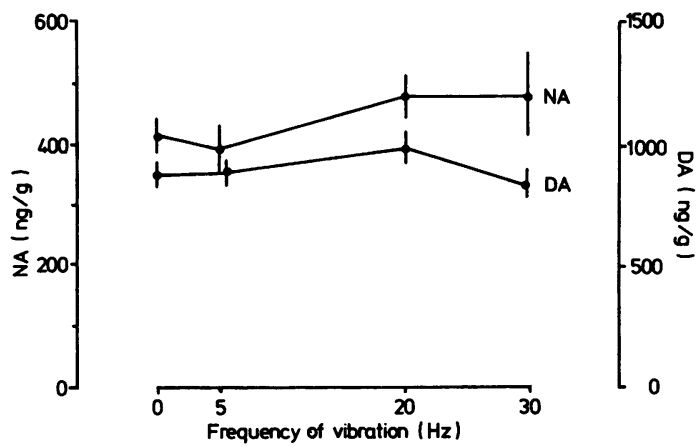

Fig 2 Effects of 240 minute vibration of different frequency and constant acceleration of $0.4 G$ on brain NA and $D A$ concentrations. Each point represents mean \pm $S E M$ of four rats. No significant changes were observed in both NA and DA concentrations. 


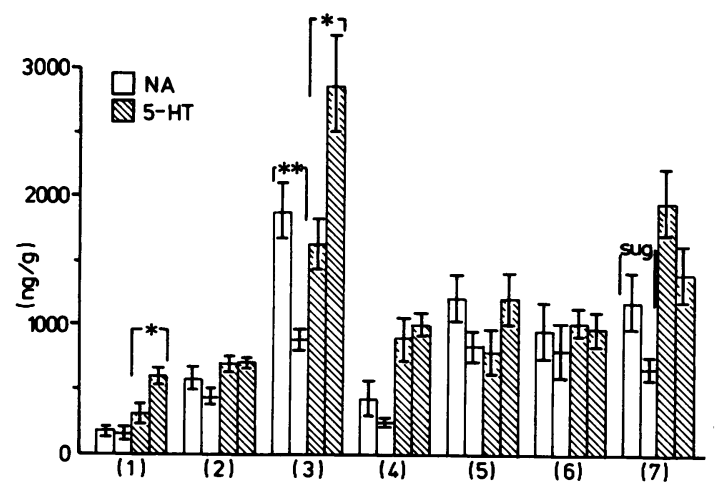

Fig 3 Effects of vibration $5.0 \mathrm{G}$ and $20 \mathrm{~Hz}$ frequency on $N A$ and 5-HT concentrations in rat brain regions. For each region left bars indicate control and right bars vibration exposed animals. Numbers in parentheses indicate brain regions: 1 cerebellum, 2 medulla oblongata, 3 hypothalamus, 4 striatum, 5 mid-brain, 6 cortex, and 7 hippocampus. Each point represents mean $\pm S E M$ of four rats. ${ }^{* *} p<0.01 ;{ }^{*} p<0.05$; sug $p<0.10$ (t test).

brain regions after various stresses. ${ }^{4-6}$ In our experiments the NA content of the brain of rats exposed to vibration decreased with increased acceleration. At the highest acceleration of $5.0 \mathrm{G}$ the decrease was as high as $57 \%$. When the frequency of vibration was changed under constant acceleration, however, no significant differences were observed be-

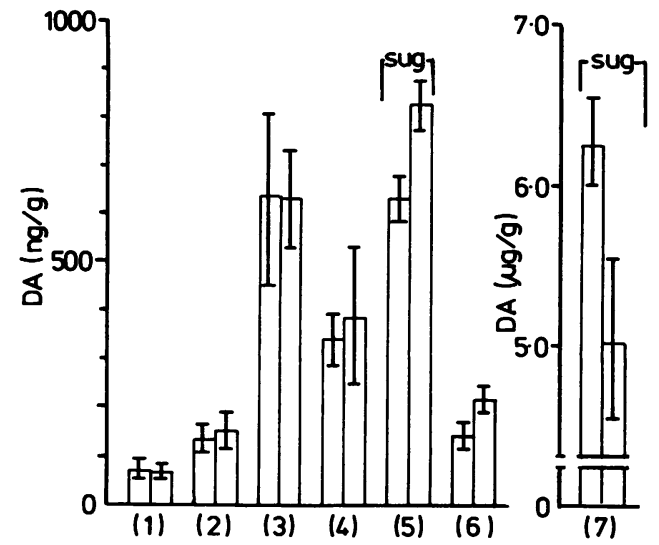

Fig 4 Effect of vibration $5.0 \mathrm{G}$ and $20 \mathrm{~Hz}$ frequency on $D A$ concentrations in rat brain regions. For each region left bars indicate control and right bars vibration exposed animals. Numbers in parentheses indicate brain regions: 1 cerebellum, 2 medulla oblongata, 3 hypothalamus, 4 mid-brain, 5 cortex, 6 hippocampus, and 7 striatum. Each point represents mean $\pm S E M$ of four rats. sug $p<0.10$ ( $t$ test). tween the exposed and control rats. We suggest, therefore, that the change in NA content depends on the intensity of vibration. Moreover, the decrease of the NA content in the whole brain is associated with a substantial decrease in the hypothalamus and a smaller decrease in the hippocampus.

Bliss et al reported that the NA content of the whole brain was decreased to $71 \%$ by an electrical shock in the foot? and similar effect was observed after forced swimming. ${ }^{8}$ Ritter and Pelzer, who determined NA in the hypothalamus and the telencephalon immediately after 60 minutes of exposure to cold or electrical shock, observed a remarkable depletion in the NA content of the hypothalamus. ${ }^{9}$ Our experiments show that vibration stress has the same effect on the NA content of the brain and this effect depends on the intensity of vibration.

The content of DA in the whole brain was scarcely affected by acceleration or by vibration frequency, but the DA tended to decrease in the striatum and increase in the cortex.

It must be pointed out that Bliss et al did not find significant changes in the DA content of rat whole brain after electrical shock, although another study has reported a $65 \%$ depletion in the DA concentration of the substantia nigra. ${ }^{10}$

Like NA, 5-HT changed with vibration acceleration more than with frequency. ${ }^{11}$ 5-HT concentration was increased. in two brain regions, the hypothalamus and cerebellum, whereas the concentration of NA decreased. The interpretation of these findings needs further investigation.

\section{References}

' Glowinski J, Iversen LL. Regional studies of catecholamines in the rat brain-I. J Neurochem 1966;13:655-69.

${ }^{2}$ Karasawa T, Fukuda K, Yoshida K, Shimizu M. A double column procedure for simultaneous estimation of norepinephrine, normetanephrine, dopamine, 3-methoxytyramine and 5-hydroxytryptamine in brain tissues. Jpn J Pharmacol 1975;25:727-36.

${ }^{3}$ Bogdanski DF, Pletsher A, Brodie BB, Udenfried S. Identification and assay of serotonin in brain. J Pharmacol Exp Ther 1956;117:82-8.

4 Thoa NB, Tizabi Y, Jacobowiz DM. The effect of isolation on catecholamines concentration and turnover in discrete areas of the rat brain. Brain Res 1977;131:259-69.

${ }^{5}$ Palcovits M, Kobayashi RM, Kizer JS. Effects of stress on catecholamines and tyrosine hydroxylase activity of individual hypothalamic nuclei. Neuroendocrinol 1975; 18:144-53.

- Okada A, Ariizumi M, Okamoto G. Changes in cerebral norepinephrine induced by vibration or noise stress. Eur $J$ Appl Physiol 1983;52:94-7.

' Bliss EL, Ailion J, Zwanziger J. Metabolism of norepinephrine, serotonin and dopamine in rat brain with stress. J Pharmacol Exp Therap 1968;164:122-34.

${ }^{8}$ Weiss JM, Glazer HI, Pohorecky LA. Effects of chronic exposure to stressors on avoidance-escape behavior and on brain norepinephrine. Psychosom Med 1975;37:522-34. 
' Ritter S, Pelzer NL. Magnitude of stress-induced brain norepinephrine depletion varies with age. Brain Res $1978 ; 152: 170-5$

${ }^{10}$ Fadda F, Argiolas A, Melis MR, Tissari AH, Orali PL, Gessa GL. Stress-induced increase in 3, 4-dihydroxyphenylacetic acid (DOPAC) levels in the cerebral cortex and in N. accumbens: reversal by diazepam. Life Sci 1978;23:2219-24.

" Ariizumi M, Okada A. Effect of whole body vibration on the rat brain content of serotonin and plasma corticosterone. Eur $J$ Appl Physiol 1983;52:15-9.

\section{The January 1985 issue}

\section{THE JANUARY 1985 ISSUE CONTAINS THE FOLLOWING PAPERS}

Mortality of factory workers in east London 193380 MURIAL L NEWHOUSE, G BERRY, AND J C WAGNER

Combined effect of asbestos and smoking on mortality from lung cancer and mesothelioma in factory workers G BERRY, M L NEWHOUSE, AND P ANTONIS

Cytogenetic, immunological, and haematological effects in workers in an ethylene oxide manufacturing plant $\mathrm{N}$ J VAN SITTERT, G DE JONG, M G CLARE, R DAVIES, B J DEAN, L J WREN, AND A S WRIGHT

Exposure to glyceryl trinitrate during gun powder production: plasma glyceryl trinitrate concentration, elimination kinetics, and discomfort among production workers K GJESDAL, S BILLE, J E BREDESEN, E BJøRGE, B HALVORSEN, K LANGSETH, P K M LUNDE, AND E SIVERTSSEN

Effects of intervention on the cardiovascular mortality of workers exposed to carbon disulphide: a 15 year follow up M NURMINEN AND S HERNBERG

Morphometric and elemental microanalytical studies of human lung in health and disease K A SIEGESMUND, A FUNAHASHI, AND D E YORDE
Lung function, atopy, specific hypersensitivity, and smoking of workers in the enzyme detergent industry over 11 years D F S FLOOD, R E BLOFELD, C F BRUCE, J I HEWITT, C P JUNIPER, AND D M ROBERTS

Occupational asthma due to an emulsified oil mist M S HENDY, B E BEATTIE, AND P S BURGE

Pulmonary function of London firemen D B DOUGLAS, R B DOUGLAS, D OAKES, AND G SCOTT

Effect of commercial diving on ventilatory function S J WATT

Determination of diethyllead in the urine by flameless atomic absorption spectrometry Z TURLAKIEWICZ, M JAKUBOWSKI, AND J CHMIELNICKA

\section{Short report}

Effects of radiant heat in fire fighting instructors C J STEVENSON

\section{Correspondence}

Book review

Notice

Copies are still available and may be obtained from the PUBLISHING MANAGER, BRITISH MEDICAL ASSOCIATION, TAVISTOCK SQUARE, LONDON WC1H 9JR, price $£ 4 \cdot 25$ (USA \$9.20), including postage. 